Psicologia e ciências humanas

\title{
Transitando entre Espinosa e Nietzsche para a compreensão de possibilidades de ação transdisciplinar em equipes de saúde
}

\author{
Barbara Eleonora Bezerra Cabral
}

\section{SciELO Books / SciELO Livros / SciELO Libros}

CABRAL, B.E.B. Transitando entre Espinosa e Nietzsche para a compreensão de possibilidades de ação transdisciplinar em equipes de saúde. In: SANTIAGO, A.M.S., and FONSÊCA, A.L.B., comp. Psicologia e suas interfaces: estudos interdisciplinares [online]. Salvador: EDUFBA, 2016, pp. 91-111. ISBN 978-85-232-2007-5. https://doi.org/10.7476/9788523220075.0004.

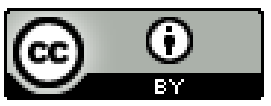

All the contents of this work, except where otherwise noted, is licensed under a Creative Commons Attribution 4.0 International license.

Todo o conteúdo deste trabalho, exceto quando houver ressalva, é publicado sob a licença Creative Commons Atribição $\underline{4.0}$. 


\title{
Transitando entre Espinosa ${ }^{1}$ e Nietzsche para a compreensão de possibilidades de ação transdisciplinar em equipes de saúde
}

\author{
Barbara Eleonora Bezerra Cabral
}

\section{Da proposta do texto}

Destinando-me a compreender as possibilidades de ação transdisciplinar em saúde, tomando como cenário o trabalho cotidiano de equipes do Núcleo de Apoio à Saúde da Família (Nasf) de Juazeiro-BA e Petrolina-PE, ${ }^{2}$ mergulhei em alguns aspectos das propostas filosóficas de Espinosa e Nietzsche, pensadores que se identificam quanto a um ponto crucial: a valorização da vida em sua imanência. Ima-

1 Neste Capítulo, optou-se pela grafia aportuguesada do nome Spinoza que será grafado Espinosa. Válido para variações do termo.

2 A pesquisa foi desenvolvida no doutorado, realizado no Programa de Pós-Graduação em Psicologia da Universidade Federal do Espírito Santo (UFES), sob orientação da profa. Angela Nobre de Andrade, tendo a tese sido defendida em 2011. O Nasf constitui um dispositivo da Atenção Básica, caracterizando-se como uma equipe de composição multidisciplinar, que deve atuar no território, principalmente no apoio matricial às equipes de Saúde da Família. 
nência, nesse caso, remete à vida em ato, acontecendo, na existência imediata de cada ser, em sua relação com o mundo em que habita.

Esses dois filósofos tornaram-se interlocutores fundamentais, tanto no processo de imersão em campo quanto na produção de interpretações com base na matéria-prima construída. Este texto se propõe a apresentar os principais recortes feitos nesse sentido, estando longe de esgotar a complexidade das questões tematizadas pelos autores, porém pretendendo lançar algum facho de luz em filigranas do seu pensamento que pareceram sintonizadas aos objetivos da pesquisa.

\section{A ética compreendida a partir dos efeitos dos encontros}

Em Espinosa, interessou-me, sobretudo, a discussão acerca da ética. Como ponto de partida para uma breve apresentação de sua compreensão a respeito dessa temática, torna-se fundamental explicitar que a grande tese teórica do espinosismo é a de que existe uma única substância, que possui uma infinidade de atributos. (DELEUZE, 2002) Assim, todas as "criaturas" são modos desses atributos ou modificação dessa substância primária, que é Deus. Destaca-se que, para este filósofo, Deus sive natura, ou seja, Deus corresponde à potência da natureza, Deus é natureza, portanto, uma força atual, infinita e imanente, o que fundamentaria a negação da existência de um Deus moral, transcendente, criador. Em função das teses práticas daí decorrentes, que fundamentam uma denúncia da "consciência”, dos “valores" e das "paixões tristes", Espinosa foi bastante criticado e odiado em sua época, sob as acusações de materialista, imoralista e ateu. ${ }^{3}$

Espinosa recusa uma superioridade da coisa pensante (mente) sobre a coisa extensa (corpo) ou vice-versa, ao mesmo tempo em que nega qualquer ligação de causalidade entre ambos, tese teórica conhecida pelo nome de paralelismo. (DELEUZE, 2002) Nas palavras de Espinosa (2009, p. 100), encontramos:

3 Espinosa viveu de 1632 a 1677, tendo nascido na Holanda, judeu, sendo expulso posteriormente da comunidade judaica em função de suas produções filosóficas. 
[...] a mente e o corpo são uma só e mesma coisa, a qual é concebida ora sob o atributo do pensamento, ora sob o da extensão. [...] a ordem das ações e das paixões de nosso corpo é simultânea, em natureza, à ordem das ações e das paixões da mente.

Para Espinosa (apud DELEUZE, 2002), o homem se constitui de mente e corpo, sendo que o corpo existe tal como o sentimos, de modo que a mente está unida ao corpo.

A compreensão dessa união mente-corpo tem, portanto, acepção bem peculiar no contexto da filosofia espinosana, a ponto de se afirmar que a mente somente pode ser conhecida a partir das ideias das afecções do corpo, ou seja, as afecções do corpo são tomadas como via de conhecimento da própria mente. Nessa linha de raciocínio, o conhecimento do corpo se dá por suas afecções, pelas quais a mente constrói ideias a respeito do corpo e de si. Tamanha é a imbricação corpo-mente que não se pode compreender essa relação a partir de uma perspectiva dicotômica.

Com base nessa compreensão, Espinosa (apud DELEUZE, 2002) defende que a primazia da mente em relação ao corpo, característica da tradição do pensamento filosófico do século XVII - que reverbera até os dias atuais -, não se sustentaria. Revela que a própria experiência humana fundamenta seu argumento e, como uma das tentativas de demonstração de sua tese, recorre, dentre outros, ao exemplo dos sonâmbulos, cujos atos ultrapassam a compreensão das possibilidades do corpo e da própria mente.

Para Deleuze (2002, p. 24), a tese do paralelismo implicaria a consequência de que “[...] o que é ação na alma é também necessariamente ação no corpo, o que é paixão no corpo é por sua vez necessariamente paixão na alma”. Assume-se, então, que o corpo ultrapassa o conhecimento que temos dele bem como o pensamento ultrapassa a consciência que dele temos, a ponto de esta ser considerada como o lugar de uma ilusão, apenas recolhendo efeitos e ignorando as causas. A ordem das causas seria uma composição ou decomposição de 
relações entre os corpos, afetando toda a natureza, gerando um todo mais potente ou coesão de suas partes, no primeiro caso, ou destruição da coesão, no segundo.

Além da desvalorização da consciência, em proveito do pensamento, Espinosa (apud DELEUZE, 2002) propõe uma desvalorização de todos os valores transcendentes e universais, especialmente do bem e do mal, em proveito do bom e do mau. Isso implica um questionamento das verdades universalizantes e das leis eternas, defendidas por uma concepção metafísica de conhecimento e mundo. Em substituição às categorias universais de bem e mal, propõe bom e mau, como aspectos que caracterizariam as relações diversas entre corpos. O bom acontece se um corpo compõe diretamente sua relação com outro corpo, aumentando sua potência, e o mau, por sua vez, surge se um corpo, na relação com outro corpo, o decompõe, reduzindo, portanto, sua potência.

Cabe destacar que potência não é compreendida como essência ou substância, mas como ato, portanto, sendo. Na ontologia espinosana, de acordo com Chauí (2003), o homem é concebido como parte da natureza, ou seja, parte do todo natural. Sendo assim, sua essência corresponde à sua potência de agir, também nomeada como conatus ou direito natural. Sendo tomado como ser vivo e constituinte da natureza, o homem tem sua potência de ação definida não pela razão, e sim pelo desejo:

Se, assim, a natureza humana estivesse disposta de tal modo que os homens vivessem seguindo unicamente as prescrições da razão, e se todo o seu esforço tendesse apenas para isso, o direito natural, enquanto se considerasse o que é próprio ao gênero humano, seria determinado tão-só pela capacidade de razão. Mas os homens são menos conduzidos pela razão do que pelo desejo cego, e, portanto, a capacidade natural dos homens, isto é, o seu direito natural, deve ser definido não

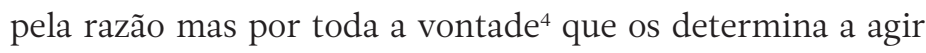

4 Capacidade natural corresponde à potência natural e vontade, a desejo, conforme encontrado no mesmo frag'mento citado em Chauí (2003). Embora se entenda a importância da tradução, 
e através da qual se esforçam por se conservar. Confesso, na verdade, que esses desejos não originados na razão não são ações como paixões humanas. Mas, tratando-se aqui do poder universal da natureza, que é a mesma coisa que o direito natural, não podemos reconhecer nenhuma diferença entre os desejos que a razão nos engendra e os que têm outra origem: uns e outros, de fato, são efeitos da natureza e manifestam a força natural pela qual o homem se esforça por perseverar no seu ser. (SPINOZA, 2005, p. 30)

O conatus do homem corresponderia à essência atual do corpo e da mente, distinguindo-se de uma inclinação ou potencial. Assim, potência não é virtualidade, mas poder atual. Seria caracterizado como uma força sempre em ato. Na parte III de sua Ética, Espinosa (2009, p. 105) define como essência atual "o esforço pelo qual cada coisa se esforça por perseverar em seu ser”. O ser é sempre singular, sendo essa sua essência. O que o ser humano compartilha com outros seres, particularmente outros humanos, são propriedades gerais comuns, e não sua essência.

Conforme Chauí (2003, p. 211) aponta, "um ser humano não é a realização particular de uma essência universal ou de uma natureza humana universal, mas é uma singularidade por sua própria essência”. Disso decorre que a essência de um ser singular são suas operações e ações, realizadas para que se mantenha na existência, sendo anteriores à sua caracterização como racionais ou irracionais, certas ou erradas. A essência singular do ser humano se relaciona à sua atividade. Os atos humanos não poderiam ser compreendidos meramente numa perspectiva teleológica, portanto. Sendo o conatus a essência atual de um ser singular, daí decorre a compreensão de que

identificando-se maior coerência em Chauí, optou-se por manter a tradução encontrada na edição consultada. Inclusive, na parte III de sua Ética, Espinosa (2009) distingue vontade de desejo: vontade indica o esforço de uma coisa por perseverar em seu ser, quando referido apenas à mente, ao passo que desejo (ou apetite) indica o esforço quando referido à mente e ao corpo simultaneamente. Mais precisamente, aponta que desejo é o apetite juntamente com a consciência que se tem dele. 
[...] apetites, impulsos e volições não são inclinações ou tendências virtuais que se atualizariam ao encontrar uma finalidade de realização, e sim aspectos atuais do conatus e, por isso mesmo, são causas eficientes que operam determinadas por outras causas eficientes e não em vista de fins. (CHAUÍ, 2003, p. 211)

Retomando a discussão em torno dos sentidos de bom e mau, destaca-se que haveria dois possíveis: num primeiro, objetivo, mas relativo e parcial, trata-se do que convém ou não convém à nossa natureza. Num outro sentido, subjetivo, qualifica dois tipos ou modos de existência do homem:

[...] será dito bom (ou livre, ou razoável, ou forte) aquele que se esforça, tanto quanto pode, por organizar os encontros, por se unir ao que convém à sua natureza, por compor a sua relação com relações combináveis e, por esse meio, aumentar sua potência. Pois bondade tem a ver com o dinamismo, a potência e a composição de potências. Dir-se-á mau, ou escravo, ou fraco, ou insensato, aquele que vive ao acaso dos encontros, que se contenta em sofrer as consequências, pronto a gemer e a acusar toda vez que o efeito sofrido se mostra contrário e lhe revela a sua própria impotência. (DELEUZE, 2002, p. 29)

Assim, Espinosa elabora sua ética como uma tipologia dos modos de existência imanentes, sem referência a valores transcendentes, com caráter de verdades eternas, universais ou absolutas,compreendendo que esta referência caberia à moral, que se baseia num sistema de julgamento. Em meio à discussão sobre ética e moral, o autor constrói uma filosofia da vida, denunciando tudo o que nos separa da vida, particularmente os valores transcendentes que contra ela se orientam, depreciando-lhe.

Nessa frequência de valorização da vida, a ética espinosana se fundamenta nos efeitos das composições e decomposições características das relações entre os seres, tal como indicado. Esses efeitos 
decorrem dos afetos, tomados como diapasão para avaliar o que é bom ou mau. É no mínimo curiosa sua compreensão de que

[...] não é por julgarmos uma coisa boa que nos esforçamos por ela, que a queremos, que a apetecemos, que a desejamos, mas, ao contrário, é por nos esforçarmos por ela, por querê-la, por apetecê-la, por desejá-la, que a julgamos boa. (SPINOZA, 2009, p. 106)

O afeto corresponde às "afecções do corpo, pelas quais sua potência de agir é aumentada ou diminuída, estimulada ou refreada, e, ao mesmo tempo, as ideias dessas afecções”. (SPINOZA, 2009, p. 98)

Relembrando a tese do paralelismo, cabe pontuar que se algo aumenta ou diminui a potência de agir de nosso corpo, a ideia dessa coisa estimula ou refreia a potência de pensar de nossa mente. De acordo com a perspectiva espinosana, a intensidade da força do conatus pode aumentar ou diminuir a depender da forma como cada singularidade se relaciona com outras em seu esforço por sua conservação: há diminuição se a singularidade for afetada pelas outras de modo a se tornar delas dependente ao passo que o aumento ocorre se a singularidade não perder independência e autonomia ao afetar e ser afetada por outras. Essa modulação da intensidade ou força do conatus indica uma realização adequada ou inadequada do esforço de autoconservação. Diz-se que:

A realização é inadequada quando o conatus individual é apenas uma causa parcial das operações do corpo e da mente porque é determinado pela potência de causas externas que o impelem nessa ou naquela direção, dominando-o e diminuindo sua força. A realização é adequada quando o conatus aumenta sua força por ser a causa total e completa das ações que realiza, relacionando-se com as forças exteriores sem ser impelido, dirigido ou dominado por elas; o nome da inadequação é paixão; o nome da adequação é ação. (CHAUÍ, 2003, p. 212)

Considerando o ser vivo como uma essência singular, ou seja, um grau de potência, Espinosa acredita que "[...] a essa essência corresponde uma relação característica; a esse grau de potência corres- 
ponde certo poder de ser afetado”. (DELEUZE, 2002, p. 33) A ética se refere a uma etologia que considera o poder de ser afetado, para os seres vivos de forma geral. Como indicado no fragmento acima, retirado de Chauí, no caso da etologia dos homens, existem duas espécies de afecções: as ações (explicadas pela natureza do indivíduo afetado, derivando de sua essência) e as paixões(explicadas por outra coisa, derivando do exterior). "O próprio da paixão, em qualquer caso, consiste em preencher a nossa capacidade de sermos afetados, separando-nos, ao mesmo tempo de nossa capacidade de agir, mantendo-nos separado dessa potência.” (DELEUZE, 2002, p. 33)

Desse modo, Espinosa (2009) compreende que dos encontros entre os corpos e suas mútuas afetações, brotam paixões tristes ou alegres. As paixões são alegres ou tristes conforme tenha sido aumentada ou diminuída nossa potência para agir, a partir dos encontros e relações em que nos enredamos. Assim, é

[...] à medida que uma coisa nos afeta de alegria ou de tristeza que nós a chamamos boa ou má. Portanto, o conhecimento do bem e do mal nada mais é do que a ideia de alegria ou tristeza que se segue necessariamente desse afeto de alegria ou de tristeza. (SPINOZA, 2009, p. 163)

Essa ideia de alegria ou tristeza não está descolada do afeto, da mesma forma que a mente não se descola do corpo: o conhecimento do bem e do mal é o próprio afeto, na medida em que estamos conscientes dele. Os afetos da alegria e da tristeza podem ser explicados, portanto, pelas paixões, que surgem quando não somos causa adequada das afecções, ou seja, quando não passamos de sua causa parcial, dado haver a intervenção e o predomínio de causas externas.

Nesse contexto, agir e padecer são dois modos possíveis de existência dos seres, que se alternam ao longo da vida. Segundo Espinosa (2009, p. 107), por alegria se compreende “[...] uma paixão pela qual a mente passa a uma perfeição maior”, e, por tristeza, “[...] uma paixão pela qual a mente passa a uma perfeição menor”. Torna-se importante esclarecer que, por perfeição, Espinosa (2009) compreende a pró- 
pria essência de uma coisa e a sua realidade. Enfatiza que, se a essência da mente corresponde a uma afirmação da existência atual de seu corpo, e perfeição é a própria essência de uma coisa, decorre que “[...] a mente passa a uma maior ou menor perfeição quando lhe acontece afirmar, de seu corpo ou qualquer de suas partes, algo que envolve mais ou menos realidade do que antes". (SPINOZA, 2009, p.152)

Passar a uma perfeição maior, no caso da alegria, implica um ato pelo qual a potência de agir é aumentada ou estimulada: já na tristeza, está implicado um ato que promove uma diminuição da potência de agir. Desejo, alegria e tristeza se caracterizam, segundo o filósofo, como os afetos primários, de onde brotam todos os outros. Espinosa (2009) defende que a ética está fundamentalmente relacionada à alegria, aos bons encontros, que compõem e aumentam a potência de agir, alargando as possibilidades dos humanos diante da vida, uma vez que se tornam menos sujeitos à intensidade das causas externas, ainda que um domínio absoluto sobre os afetos que brotam dos encontros entre corpos seja da ordem do impossível.

Nesse sentido, não se pode ignorar ou almejar eliminar as interferências de causas externas na própria vida, mas a elas não se atribui um peso determinista, dada a possibilidade de ampliar a potência de ação ao mesmo tempo em que se reduz o padecimento. Seria interessante, nessa perspectiva, que os humanos buscassem um alargamento contínuo de sua potência de ação, de modo a privilegiar as paixões alegres no contexto dos seus encontros na vida. Ao longo deles, os corpos são movidos de diferentes maneiras, havendo infinitas possibilidades de composições (paixões alegres) e decomposições (paixões tristes):

$[\ldots]$ todas as maneiras pelas quais um corpo qualquer é afetado por outro seguem-se da natureza do corpo afetado e, ao mesmo tempo, da natureza do corpo que o afeta. Assim, um só e mesmo corpo, em razão da diferença de natureza dos corpos que o movem, é movido de diferentes maneiras, e, inversamente, corpos diferentes são movidos de diferentes maneiras por um só e mesmo corpo. (SPINOZA, 2009, p. 63) 
Pode-se depreender da ética de Espinosa, portanto, que um agir ético estaria associado à produção, criação de novos modos, favorecedores de vida e de sua expansão, a partir do encontro entre os seres e das afetações dele decorrentes, que implicam aumento da potência de ação. Considero pertinente recorrer à compreensão de potência de ação, por Sawaia (2003), a partir de Espinosa, dado sintonizar-se com o aspecto ora discutido, qual seja, a dinâmica das afetações a partir dos encontros como um motor para a transformação de modos relacionais no contexto da atuação em saúde. Tratar-se-ia da

[...] capacidade de um corpo ser afetado por outro, num processo de possibilidade infinita de criação e de entrelaçamento nos bons e maus encontros, portanto, é quando o homem se torna causa de seus afetos e senhor de suas percepções. A potência de padecer é viver ao acaso dos encontros, joguete dos acontecimentos, pondo nos outros o sentido da própria potência de ação. (SAWAIA, 2003, p. 93)

\section{Crítica à moral e atitude genealógica}

Deleuze (2002) indica a tríplice crítica de Espinosa - à "consciência", aos "valores" e às "paixões tristes" - como as grandes semelhanças com Nietzsche,${ }^{5}$ chegando a caracterizá-lo como spinosista em alguns pontos. Penso que essa aproximação se evidencia especialmente quando este fundamenta seu projeto filosófico em uma crítica contundente dos valores morais - chamados superiores por estarem relacionados ao pensamento metafísico ocidental, hegemônico, que defende valores transcendentes, além da vida, fora do mundo, considerados como verdadeiros. O pensamento metafísico retoma e se respalda na tradição socrático-platônica, que acentua a dicotomia essência-aparência, instituindo a supremacia da essência, tomada

5 A produção nietzschiana ocorre na segunda metade do século XIX, tendo o filósofo tido acesso ao pensamento de Espinosa, chegando inclusive a fazer rápidas referências ao seu nome em sua obra, como no prólogo de Genealogia da moral. 
como verdade, e desvalorizando a aparência, dimensionada como simulacro, erro, mentira e desvio.

Propondo a inversão disso, Nietzsche (2009) defende a necessidade de uma transvaloração dos valores, enfatizando a própria vida como critério de valor e o perspectivismo do conhecimento, em articulação com uma consideração histórica. Afirma veementemente que

[...] toda a teleologia se baseia no fato de se tratar o homem dos últimos quatro milênios como um ser eterno, para o qual se dirigem todas as coisas do mundo, desde o seu início. Mas tudo veio a ser; não existem fatos eternos: assim como não existem verdades absolutas. (NIETZSCHE, 2008, p. 16)

Assim, os valores são compreendidos como históricos, advindos ou em devir, não tendo uma existência em si, de caráter essencial, tampouco sendo eternos. Ainda que critique as dicotomias, próprias da tradição metafísica de pensamento, nesse processo de questionamento dos valores morais e da vontade de verdade, Nietzsche (2009) enfatiza a aparência, valorizando-a em contraponto à essência: importa o que é (sendo, em ato), o que se mostra, a superfície, o imediatismo da experiência, a ilusão. É o mundo sensível que constitui palco de nossas experiências, onde a própria vida acontece e em que se cria a própria existência. Esse aqui e agora constitui a imanência da vida, único lócus legítimo para avaliação da própria vida, que jamais deveria ocorrer a partir de categorias abstratas, fixas e imutáveis, exteriores ao mundo e à vida, transcendentes. A vida, em sua processualidade, não comporta uma valoração a partir de valores além do mundo, tidos como universais e absolutos.

De acordo com Machado (2002), a valorização da aparência empreendida por Nietzsche foi um modo encontrado de se contrapor à tradição socrático-platônica, indicando outras possibilidades de compreensão da produção de conhecimento, mas é importante destacar que a sua filosofia busca escapar a quaisquer dicotomias, dado instituir uma perspectiva que ultrapassa as categorias de verdade e 
erro. "Afirmar que a vida é aparência, reivindicar a positividade do falso é se insurgir contra a possibilidade de um julgamento da vida a partir de um critério de verdade; é ressaltar como a vontade absoluta de saber é um ultraje à vida.” (MACHADO, 2002, p. 106)

O projeto de transvaloração dos valores constitui o cerne do projeto filosófico nietzschiano, que pode ser caracterizado como uma filosofia do valor. (MACHADO, 2002) Para este Machado (2002), Nietzsche exortava o questionamento do valor dos valores, situando a própria vida, em sua imanência, como critério maior de avaliação. Diante desse panorama, a crítica à ciência se revelava como um dos pontos nodais da sua filosofia: estando calcada na tradição socrático- platônica, a perspectiva científica em voga era percebida por Nietzsche como sendo diretamente relacionada à moral e à vontade de verdade.

No seu pensamento, a moral é compreendida como contrária à vida, por se fundar em valores transcendentais - fixos, imutáveis e fora do mundo -, revelando-se como manifestação de fraqueza e negação dos valores mais fundamentais da vida, tomada em sua processualidade. A vontade de verdade, que move a própria ciência e o conhecimento racional, é a crença - tipicamente metafísica - de que o mais necessário é a "verdade”, tomada como essência e valor superior, que se contrapõe ao falso, ao aparente, ao superficial.

Nessa conjuntura, a vida é compreendida como força, como potência, ou melhor, como embate de forças, cuja correlação cria valores, que a direcionam seja no sentido de sua expansão e aumento ou de sua conservação e diminuição. A concepção de vida aí expressa está intimamente relacionada a um conceito nietzschiano fundamental: a vontade de potência.

A essência da vida é vontade de potência, que corresponde à “[...] primazia fundamental das forças espontâneas, agressivas, expansivas, criadoras de novas formas, interpretações e direções, forças cuja ação necessariamente precede a 'adaptação'”. (NIETZSCHE, 2009, p. 62) A vontade de potência seria operante em todo acontecer, implicando 
atividade e, portanto, alargamento de vida. Como indicado por Zaratustra, em suas andanças a vida lhe confiou um segredo, o qual revela sua essência: ela é o que deve se superar indefinidamente. (NIETZSCHE, 2005)

Sendo a vontade de potência o elemento básico da vida, em tudo ela existe. "Há muitas coisas que o vivente aprecia mais do que a vida; mas nas próximas apreciações fala a "vontade de domínio'.” (NIETZSCHE, 2005, p. 97) Mesmo quando dos embates de forças, que compõem a vida, resulta sua diminuição, pelo predomínio das forças reativas, há vontade de potência. Segundo Machado (2002), nesse caso existiria uma vontade de potência negativa ou fraca, exprimindo-se como uma vontade de nada. É o caso da moral, compreendida como a manifestação de uma vontade enfraquecida, porque vinculada a uma representação, a uma potência imaginária, em sua aliança com valores transcendentais, indicando uma atitude niilista, ou seja, de negação da vida e dos seus valores.

Em sua Genealogia da moral, Nietzsche (2009) discute as três principais figuras do niilismo: o ressentimento, a culpa ou má consciência e o ideal ascético. Em linhas gerais, o ressentimento se refere ao predomínio de forças reativas, de modo que não se assume a responsabilidade por atos ou situações, que é imputada sempre aos outros - considerados maus - ou a causas externas, implicando uma passividade e um contínuo rancor diante da vida. A culpa pode ser caracterizada como o resultado de um retorno do ressentimento ao próprio homem, sendo, em certa medida, fruto do ideal ascético. O ascetismo implica fundamentalmente uma concepção da vida como um erro, uma mentira, em favor de um mundo além, que deve ser almejado: assim, a vida é considerada apenas como uma ponte para outra existência, que deve ser ultrapassada numa condição de humildade, pobreza, castidade e abnegação. A rigor, essas três atitudes estão intimamente relacionadas, constituindo o sistema moral judaico-cristão, sustentáculo da sociedade ocidental, vigorosamente criticado por Nietzsche. 
Não se pode em absoluto esconder o que expressa realmente todo esse querer que do ideal ascético recebe sua orientação: esse ódio ao que é humano, mais ainda ao que é animal, mais ainda ao que é matéria, esse horror aos sentidos, à razão mesma, o medo da felicidade e da beleza, o anseio de afastar-se do que seja aparência, mudança, morte, devir, desejo, anseio - tudo isto significa, ousemos compreendê-lo, uma vontade de nada, uma aversão à vida, uma revolta contra os mais fundamentais pressupostos da vida, mas é e continua sendo uma vontade!... E, para repetir em conclusão o que afirmei no início: o homem preferirá ainda querer o nada a nada querer... (NIETZSCHE, 2009, p. 140, grifo do autor)

Em sua análise, Nietzsche (2009) apresenta dois modos de existência possíveis, que se alternam ao longo da vida: um relacionado ao circuito da moral plebeia ou escrava e outro, ao circuito da moral aristocrática ou nobre, privilegiando este último. A moral escrava fundamenta um modo em que predominam as forças reativas em relação às ativas, sendo, portanto, contrário à vida. A esse modo, relacionam-se as perspectivas de doença, fraqueza, adaptação, uma vez que implica negação dos instintos da vida, constituindo uma vontade de nada e favorecendo o declínio da própria vida. O diapasão característico desse modo são os valores do bem e do mal.

A moral aristocrática, por sua vez, sustenta-se na valorização dos instintos da vida, caracterizando um modo em que predomina a ação e a saúde, promovendo afirmação e, consequentemente, expansão da própria vida. A sua frequência sintoniza-se com a contínua avaliação do que é bom ou ruim. Assim, depreende-se que amoral aristocrática corresponde, na verdade, a uma ética, tal como definida por Espinosa: nesse circuito, o homem é definido por sua potência, por sua capacidade de agir, pelo que pode fazer, estando comprometido com a contínua produção de valores que promovam o alargamento das possibilidades existenciais. Tal modo só se viabilizaria a partir de uma libertação dos grilhões da moral. 
Nesse contexto, a perspectiva de grande saúde defendida por Nietzsche (2008) relaciona-se com a disponibilidade de afirmar a vida, para além dos valores de bem e de mal. Assim, esse conceito se ilumina a partir do projeto nietzschiano de transvaloração de todos os valores, indicado anteriormente como o eixo de sua proposta filosófica: questionam-se permanentemente valores tomados como categorias absolutas ou universais na avaliação da própria vida. Seu projeto filosófico vislumbra o tortuoso transitar na vida, valorizando os encontros promotores do

[...] excesso de forças plásticas, curativas, reconstrutoras e restauradoras, que é precisamente a marca da grande saúde, o excesso que dá ao espírito livre o perigoso privilégio de poder viver por experiência e oferecer-se à aventura: o privilégio de mestre do espírito livre! (NIETZSCHE, 2008, p. 11)

Oferecer-se à aventura, na vida, implica sorver a existência, afirmando o que vier, como vier, jamais numa perspectiva conformista, entretanto, pois isto seria niilista. Tomada em sua processualidade imanente, "[...] a vida (e tudo aí implicado: dor, alegria, sofrimento, desejo etc.) não tem um início ou fim a ser alcançado; não é para ser explicada ou justificada (concepção cristã), mas simplesmente afirmada”. (ANDRADE, 1999)

A proposta nietzschiana implica afirmar a vida em sua pluralidade/diversidade, estando aí o sentido do trágico, a partir da "união artística do dionisíaco e do apolíneo na tragédia”, como destaca Machado. (2002, p. 102) Esta compreensão do trágico revela, então, uma afirmação da vida, para além de uma contradição ou reconciliação de opostos:

Não se trata de um drama, mas do trágico; ou seja, o trágico não está na angústia ou na repulsa, mas na multiplicidade, na afirmação da diversidade enquanto tal. O que define o trágico é a alegria do plural, e esta alegria não é o resultado de uma sublimação, de uma purgação, de uma compensação, de uma resignação, de uma reconciliação. Trata-se de uma outra maneira de interpretar a existência, não mais recriminando a 
vida (fruto do ressentimento, da impotência), mas afirmando-a em sua pluralidade. (ANDRADE, 1999, p. 79)

Considerando o embate de forças próprio da vida, destaca-se que toda força tende a dominar e se expandir em relação às outras. Não faz sentido falar de força no singular; trata-se sempre de relação entre forças, gerando configurações diversas, em um contexto sempre plural. Entretanto, na perspectiva nietzschiana, não há um predomínio de uma força sobre a outra, que resulte na negação ou anulação de alguma delas - afirma-se sempre uma diferença. Como destaca Andrade (1999, p. 78):

[...] o que uma vontade quer não é a negação de outra vontade, mas, sim, a afirmação de uma diferença. É a partir deste conceito de hierarquia de forças e afirmação de uma vontade que Nietzsche avalia a vida, ou seja, ao interpretar qualquer configuração, temos que avaliar qual conjunto de forças está produzindo um certo tipo de valor e que direção este valor imprime à vida.

Viver no modo de um agir ético se configuraria, então, como um contínuo exercício de avaliação das forças em embate em cada situação. A perspectiva genealógica nietzschiana se baseia na avaliação do valor dos valores, implicando uma crítica ao caráter de verdade desses valores.

Explícita nessa proposta está, por conseguinte, a superação da vontade de verdade, característica da perspectiva metafísica de ciência. Avaliar o valor dos valores requer uma avaliação de sua força, ou melhor, das forças ali presentes. Assim, a genealogia envolve uma interpretação, dado que avaliação implica uma análise da configuração de forças e valores que se correlacionam numa certa situação, por sujeitos e, aqui, ganha volume o perspectivismo nietzschiano:

Existe apenas uma visão perspectiva, apenas um 'conhecer' perspectivo; e quanto mais afetos permitirmos falar sobre uma coisa, quanto mais olhos, diferentes olhos, soubermos utilizar para essa coisa, tanto mais completo será nosso 'con- 
ceito' dela, nossa 'objetividade'. Mas eliminar a vontade inteiramente, suspender os afetos todos sem exceção, supondo que o conseguíssemos: como? - não seria castrar o intelecto?... (NIETZSCHE, 2009, p. 101, grifo do autor)

Para auxiliar na compreensão da perspectiva genealógica - inclusive, assumida e experimentada na pesquisa referida no início deste texto - recorri a Foucault (2007), que diferencia "genealogia" de "pesquisa sobre a origem das coisas", destacando, entretanto, sua aliança com a História. A recusa da pesquisa da origem em Nietzsche é assim justificada:

[...] a pesquisa, nesse sentido, se esforça por recolher nela a essência exata da coisa, sua mais pura possibilidade, sua identidade cuidadosamente recolhida em si mesma, sua forma imóvel e anterior a tudo o que é externo, acidental, sucessivo. Procurar uma tal origem é tentar reencontrar 'o que era imediatamente', o 'aquilo mesmo' de uma imagem exatamente adequada a si; é tomar por acidental todas as peripécias que puderam ter acontecido, todas as astúcias, todos os disfarces; é querer tirar todas as máscaras para desvelar enfim uma identidade primeira. Ora, se o genealogista tem o cuidado de escutar a história em vez de acreditar na metafísica, o que é que ele aprende? Que atrás das coisas, há 'algo inteiramente diferente': não seu segredo essencial e sem data, mas o segredo que elas são sem essência, ou que sua essência foi construída peça por peça, a partir de figuras que lhe eram estranhas. (FOUCAULT, 2007, p. 17-18)

Compreendendo a história como o próprio corpo do devir, a genealogia considera os saberes, discursos e práticas como peças de um dispositivo político em um dado contexto sócio-histórico, marcado por acidentes e acasos, e não por linearidades. Nesse contexto, destaca-se a figura do acaso, compreendido como um "[...] risco sempre renovado da vontade de potência que a todo surgimento do acaso opõe, para controlá-lo, o risco de um acaso ainda maior”. (FOUCAULT, 2007, p. 28) Com um longo trecho retirado de Genealogia da moral, que discute um princípio fundamental a toda ciência 
histórica, encerro a caracterização de genealogia. Trata-se do princípio de que

[...] a causa da gênese de uma coisa e a sua utilidade final, a sua efetiva utilização e inserção em um sistema de finalidades, diferem toto coelo [totalmente]; de que algo existente, que de algum modo chegou a se realizar, é sempre reinterpretado para novos fins, requisitado de maneira nova, transformado e redirecionado para uma nova utilidade, por um poder que lhe é superior; de que todo acontecimento do mundo orgânico é um subjugar e assenhorear-se, e todo subjugar e assenhorear-se é uma nova interpretação, um ajuste, no qual o 'sentido' e a 'finalidade' anteriores são necessariamente obscurecidos ou obliterados. [...] Mas todos os fins, todas as utilidades são apenas indícios de que uma vontade de poder se as senhor e ou de algo menos poderoso e lhe imprimiu o sentido de uma função; e toda a história de uma 'coisa', um órgão, um uso, pode desse modo ser uma ininterrupta cadeia de signos de sempre novas interpretações e ajustes, cujas causas nem precisam estar relacionadas entre si, antes podendo se suceder e substituir de maneira meramente casual. Logo, o ‘desenvolvimento' de uma coisa, um uso, um órgão, é tudo menos o seu progressus lógico e rápido, obtido com um dispêndio mínimo de forças - mas sim a sucessão de processos de subjugamento que nela ocorrem, mais ou menos profundos, mais ou menos interdependentes, juntamente com as resistências que a cada vez encontram, as metamorfoses tentadas com o fim de defesa e reação, e também os resultados de ações contrárias bem-sucedidas. Se a forma é fluida, o 'sentido' é mais ainda [...]. (NIETZSCHE, 2009, p. 61, grifo do autor)

\section{0 sentido ético-político nas práticas sociais}

Em se tratando do exercício das profissões de saúde, visto como prática social, ao se assumir essa trilha de compreensão, há que se avaliar o conjunto de forças em confronto, em processo de contínua dominação de umas sobre as outras, conforme o contexto em que se desenvolvem 
as práticas. Diante disso, a perspectiva genealógica como ferramenta de pesquisa me pareceu bastante fértil para o tema a que me propus, uma vez que se caracteriza como um “[...] processo permanente de avaliação coletiva dos valores presentes nos diversos encontros" (ANDRADE, 1999; ANDRADE et al., 2007), adotando-se uma atitude e intenção provocativa e desconfiada.

Penso não haver como mudar estados de coisas, tão firmemente calcados em toda uma tradição dos saberes disciplinares da sociedade moderna ocidental, baseada em valores metafísicos e transcendentais, senão a partir de uma atitude provocativa, que convoque à reflexão, chacoalhando as certezas e indicando a possibilidade de construção de outros sentidos. Cabe ressaltar que a genealogia não pode ser caracterizada como um método ou técnica, que se aplique em situações específicas: “Trata-se antes, de uma postura, de um modo de estar no mundo que se presentifica em toda a ação do pesquisador, em suas experiências, olhares e falas cotidianos". (ANDRADE, 1999, p. 83)

Busquei me apropriar, portanto, da perspectiva genealógica no percurso do referido estudo, para compreender as tramas sócio-históricas em que se inserem as práticas, discursos e saberes de profissionais de saúde inseridos em equipes multiprofissionais de Nasf, provocando e buscando compreender. A genealogia foi avocada na proposta de pesquisa tanto como referencial teórico-filosófico para a discussão da temática quanto como farol a guiar o trajeto em campo, no contato com os sujeitos/interlocutores e com o cenário da pesquisa.

A pesquisa de inspiração genealógica busca não apenas conhecer, mas também transformar, destacando-se a importância da reflexão sobre a implicação ético-política do ato de pesquisar. Não existe ali neutralidade ou isenção de objetivos; há uma intenção provocativa, de questionamento de verdades estabelecidas e dos valores que as norteiam e, portanto, de construção de outros sentidos. 
Esse sentido ético-político da prática de pesquisa se refere a um posicionamento em relação aos interlocutores, ao tema pesquisado e à própria pesquisa, com permanente construção de sentido envolvendo o coletivo. Como destaca Andrade (1999, p. 86), o que vai provocando transformação é “[...] a produção de sentidos que vai sendo instituída por todos, nos diversos encontros".

Apostando no caráter interventivo da pesquisa, tal como destacado por Andrade, Morato e Schmidt (2007), compreende-se que a simples presença do pesquisador já implica alguma interferência nessa ação e, sendo assim, que seja na direção de produzir modos mais fluidos e de afirmação da multiplicidade imanente ao encontro entre sujeitos, da alteridade e da potência singular dos seres.

Experimentando tal atitude provocativa, em uma pesquisa-intervenção, deixei-me guiar em campo na perspectiva de bons encontros com os profissionais, atenta às brechas para uma ação transdisciplinar em saúde no trabalho das equipes que toparam ser interlocutoras no estudo. Ao longo do caminho, não foram poucos os episódios em que pude perceber forças promotoras de expansão de vida, de modo que foi possível delinear um sentido possível - como e a partir de algo vivido no cotidiano - para o que buscava.

O que se pode nomear de ação transdisciplinar ultrapassa prescrições de qualquer ordem, dado que reporta à ordem da invenção. Passa, assim, pela criação em ato, ganhando contornos próprios em cada contexto, a partir dos encontros e misturas que aí ocorrem. Sendo criação, poiesis, a aposta transdisciplinar está, consequentemente, para além das especialidades - sem negá-las.

Ação transdisciplinar, como algo possível e concreto, não cabe nas normatizações, implicando ousadia, transformação e, fundamentalmente, a sustentação detensão, pelo exercício de esmaecimento das fronteiras que esse agir atualiza - seguramente, não com base em uma essência ou qualquer a priori.

$\mathrm{Na}$ interlocução com o pensamento de Espinosa e Nietzsche, dentre outros, o estudo permitiu que se construísse a compreensão 
de que ação transdisciplinar só pode existir como produção coletiva, no trânsito entre o que está prescrito e a flexibilidade/inventividade diante das queixas e demandas diárias com que as equipes de saúde se deparam.

\section{Referências}

ANDRADE, Â. N. de. Avaliação genealógica. In: MENANDRO, Paulo R.; TRINDADE, Z. A.; BORLOTTI, E. B. (Org.). Pesquisa em psicologia: recriando métodos. Vitória: UFES, 1999. p. 73-87.

ANDRADE, Â. N.; MORATO, H. T. P.; SCHMIDT, M. L. S. Pesquisa interventiva em instituição: etnografia, cartografia e genealogia. In: RODRIGUES, Maria M. P., MENANDRO, P. R. M. (Org.). Lógicas metodológicas: trajetos de pesquisa em psicologia. Vitória: GM, 2007. p. 193-206.

CHAUÍ, M.Política em espinosa. São Paulo: Companhia das Letras, 2003.

DELEUZE, G. Espinosa: filosofia prática. São Paulo: Escuta, 2002.

DELEUZE, G. Os intercessores. In: DELEUZE, G. Conversações. 2. ed. São Paulo: Ed. 34, 2010. p. 155-172.

FOUCAULT, M. Nietzsche, a genealogia e a história. In: FOUCAULT, M. Microfísica do poder. 24. ed. Rio de Janeiro: Graal, 2007. p. 15-37.

MACHADO, R. Nietzsche e a verdade. 2. ed. Rio de Janeiro: Graal, 2002.

MACHADO, R. Por uma genealogia do poder. In: FOUCAULT, M. Microfísica do poder. 24. ed. Rio de Janeiro: Graal, 2007. p. 7-8.

NIETZSCHE, F. Assim falou Zaratustra. São Paulo: Martin Claret, 2005.

NIETZSCHE, F. Humano, demasiado humano. São Paulo: Companhia das Letras, 2008.

NIETZSCHE, F. Genealogia da moral. São Paulo: Companhia das Letras, 2009.

SAWAIA, B. O sentido ético-político da saúde na era do triunfo da tecnologia e do relativismo. In: GOLDENBERG, P.; MARSIGLIA, R. M. G.; GOMES, M. H. A. (Org.). 0 clássico e o novo: tendências, objetos e abordagens em ciências sociais e saúde. Rio de Janeiro: Fiocruz, 2003. p. 83-94.

SPINOZA, B. de. Tratado político. 2. ed. São Paulo: Ícone, 2005.

SPINOZA, B. de. Ética. Belo Horizonte: Autêntica, 2009. 